\title{
Investigating the influences of liquid LPG injection on spark ignition (SI) engine
}

\author{
Mohd Mustaqim Tukiman ${ }^{1,2, *}$, Norrizal Mustaffa ${ }^{1,2}$, Mas Fawzi ${ }^{1,2}$, Shahrul Azmir Osman ${ }^{1,2}$ \\ ${ }^{1}$ Faculty of Engineering Technology, ${ }^{2}$ Faculty of Mechanical and Manufacturing Engineering. \\ ${ }^{2}$ Automotive Research Group (ARG), Center for Energy and Industrial Environment Studies \\ (CEIES), Universiti Tun Hussein Onn Malaysia, 86400 Parit Raja, Batu Pahat, Johor, Malaysia.
}

\begin{abstract}
Liquefied petroleum gas (LPG) is one of the alternative fuels that becoming popular to be use in spark ignition engine (SI). This paper briefly presents the influence of energy content to the engine output of 1.6L SI engine of Proton Gen 2. The engine was coupled to a chassis dynamometer and few related apparatus were employed in determine the engine behavior. All data collected were illustrated in graph for further analysis. The engine shows comparable engine output, however, the engine requires some tuning in order to fully utilize the energy content of LPG.
\end{abstract}

\section{Introduction}

LPG is a clean fuel and also known as "Autogas". LPG consists of a mixture of propane $\left(\mathrm{C}_{3} \mathrm{H}_{8}\right)$ and butane $\left(\mathrm{C}_{4} \mathrm{H}_{10}\right)$. Presently, LPG is one of the alternative fuels that received much attention as a replacement of traditional fuels due to their economical costs, high octane numbers, high calorific values, availability in large volume and lower polluting exhaust emissions The usage of LPG especially in SI engine has broadly been used in a few countries such as Italy, Turkey, Russia and Korea [1].

The usage of LPG as alternative fuel especially in gasoline engine gives many advantages especially in reducing dangerous knocking phenomena while running the engine at the medium high load condition and offers better exhaust emissions production [2]. It's also provides better cold start performance in gasoline engine because its rate of vaporization is very fast during the intake stroke and the amount of homogeneous mixture in the combustion chamber is substantially increased [3-6]. Therefore, excessive enrichment of the air-fuel ratio at low coolant temperature is discarded.

Currently, the conversion technology of SI engine into the LPG system had been expanded since it was introduced. The technology continues to grow as the emissions regulation became stringent. Based on the LPG delivery and system control, LPG generation and technology in SI engine may be categorized into five generations $[7,8]$. The first four generations run on gaseous LPG and the fifth generation operate with liquid LPG. Table 1 shows the summary of the LPG generation in SI engine.

The present work aims to characterize the engine output with respect to the energy content of the gasoline and LPG at various throttle position (TP). The engine performance

\footnotetext{
* Corresponding author: mohdmustaqimakim@gmail.com
} 
and exhaust emissions were examined. Mapping of the air-fuel mixing for each TP also was recorded for the tested engine.

Table 1. LPG generations $[7,8]$.

\begin{tabular}{|c|l|}
\hline Generation & \multicolumn{1}{c|}{ Description } \\
\hline First & $\begin{array}{l}\text { Mechanically controlled LPG carburetion system, open loop LPG system, } \\
\text { suitable for carburetor engine. Also known as the Induction system. } \\
\text { Simplest type of LPG kit. Introduces gas into the engine in a vapor form } \\
\text { through the inlet manifold. }\end{array}$ \\
\hline Second & $\begin{array}{l}\text { Electronically controlled, close loop, single point injection LPG system, } \\
\text { suitable for early Electronic Fuel Injection (EFI) gasoline engine. }\end{array}$ \\
\hline Third & Multipoint injection LPG system. \\
\hline Fourth & $\begin{array}{l}\text { Multipoint sequential injection also known as the Sequential Gas Injection } \\
\text { System (SGIS). Injects LPG as a vapor for each cylinder very close to the } \\
\text { inlet valves. }\end{array}$ \\
\hline Fifth & $\begin{array}{l}\text { Multipoint sequential liquid LPG injection, Unlike the first to fourth } \\
\text { generation, LPG is fed into the engine in its liquid form and without } \\
\text { vaporizing. }\end{array}$ \\
\hline
\end{tabular}

\subsection{Energy content}

Each fuel has different energy content and this energy content will significantly affect the outcomes of combustion especially in internal combustion engine. In view of gasoline and LPG, the energy content per weight was shown in Table 2 and it's presented that energy content of LPG was slightly higher as compared to the gasoline fuel. Logically, the engine performance produced by LPG will be higher than gasoline but the benefit of LPG energy content only may be useful with the proper setting and adjustment. This is due to the LPG is a gaseous fuel meanwhile gasoline is a liquid fuel. In this study, the fifth generation of LPG was used.

Table 2. Energy content of gasoline and LPG [9-11].

\begin{tabular}{|c|c|}
\hline Gasoline (kJ/kg) & LPG (kJ/kg) \\
\hline 43500 & 46500 \\
\hline
\end{tabular}

\section{Experimental details}

\subsection{Test engine}

A 1.6 liter spark ignition engine naturally aspirated of Proton Gen-2 was selected as the test vehicle. The detailed specifications of the engine are as summarized in Table 3.

\subsection{Experimental apparatus}

In order to obtain the experimental data of the dedicated SI engine and LPG converted SI engine, series of experiments were carried out in analyzing the engine characteristics. The engine was coupled to the Dynapack Chassis Dynamometer that produced the performance data such as torque and brake power. The chassis dynamometer used is capable to run and simulate various types of engine testing including actual road operation. The exhaust emissions of the engine were captured using Autocheck Gas 4/5 emissions analyzer. The sampling time of the emissions analyzer was setup at 5 seconds for every measurement 
taken. The mass flow rate of fuel was measured using Ono Sokki fuel flow detector (FZ2100) that employed coriolis principle. The injection duration and TP were monitored real time during experiments by scan tool Bosch KTS570. In fixing the TP at certain percentage for example at $25 \% \mathrm{TP}$, a special tool for pedal press was employed. For the LPG operation, dedicated software was used to determine the injection duration. Schematic diagram of the experimental setup is shown in Fig. 1.

Table 3. Proton Gen 2 engine specifications.

\begin{tabular}{|l|l|}
\hline Engine model & $\mathrm{S} 4 \mathrm{PH}-1.6$ \\
\hline Number of cylinders & 4 \\
\hline Orientation & East-West \\
\hline Valve train & DOHC $16 \mathrm{~V}$ \\
\hline Combustion chamber & Pentroof type \\
\hline Bore x stroke & $76.0 \mathrm{~mm} \times 88.0 \mathrm{~mm}$ \\
\hline Compression ratio & $10.0: 1$ \\
\hline Fuel injection & Indirect injection (MPI) \\
\hline Lubrication system & Pressure feed, full-flow filtration \\
\hline Cooling system & Water-cooled \\
\hline Maximum torque & $148 \mathrm{Nm}(4000 \mathrm{rpm})$ \\
\hline Maximum power & $110 \mathrm{hp}(6000 \mathrm{rpm})$ \\
\hline
\end{tabular}

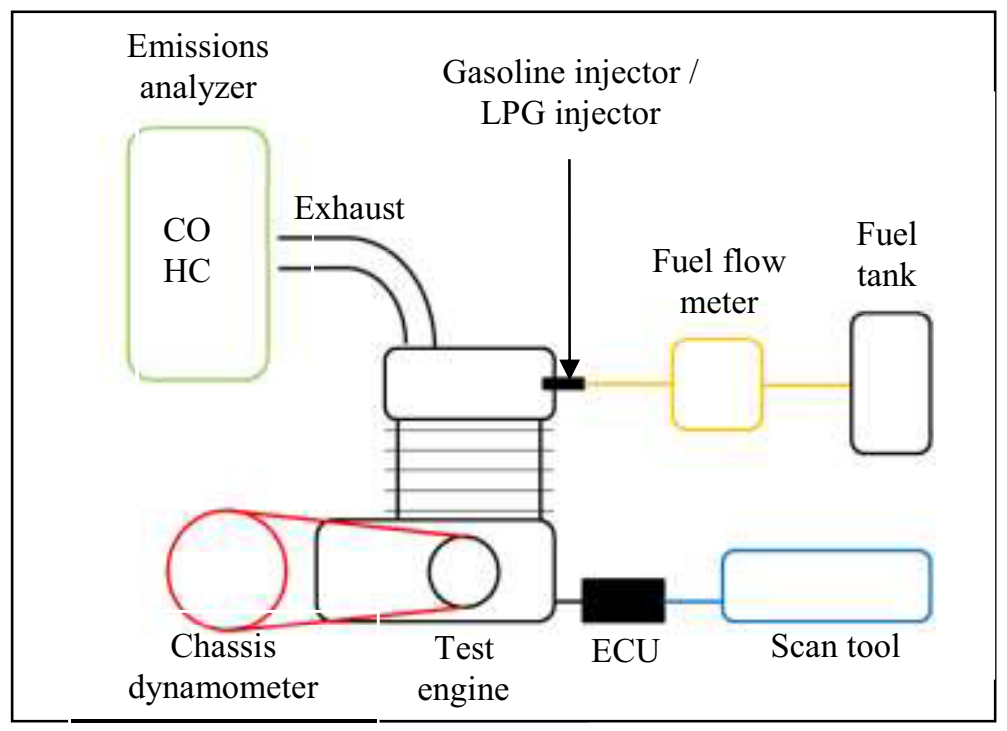

Fig. 1. Schematic diagram of experimental setup.

\subsection{Experimental methodology}

The steady state test was selected to evaluate complete this study. Steady state means the dedicated engine will be tested based on engine speed starts with the idling condition up to 4000rpm with the increment of 500rpm. The TP was varies at four different positions that were $25 \%, 50 \%, 75 \%$ and $100 \%$ for each engine speed tested. Table 4 described the details of the steady state test conditions conducted. All the experiments were repeated three times for each operating condition in reducing the error and obtain the trustable results. 
Table 4. Proton Gen 2 engine specifications.

\begin{tabular}{|c|c|}
\hline Engine speed (rpm) & Throttle position (\%) \\
\hline Idling & \multirow{7}{*}{$\begin{array}{c}25 \\
50 \\
75 \\
100\end{array}$} \\
\hline 1500 & \\
\hline 2000 & \\
\hline 2500 & \\
\hline 3000 & \\
\hline 3500 & \\
\hline 4000 & \\
\hline
\end{tabular}

\section{Results and discussion}

Fig. 2 shows the brake thermal efficiency (BTE) of the tested engine for both gasoline and LPG fuels at four different TP. The BTE of gasoline at all TP was found increase as the engine speed increase meanwhile the BTE of LPG was found slightly decrease with the increment of engine speed. As the energy content is the function of BTE, it clearly described the effectiveness of the engine transform the energy content of both tested fuels into mechanical energy. Based on Fig. 2, LPG has better BTE at below 3000 engine speed and gasoline shows superior BTE after 3000 engine speed onwards. It clearly described that the engine running by gasoline has poor performance at low engine speed and only effective at higher engine speed. This may be attributed to the engine characteristic that has bad engine setting and tuning by manufacturer at its low engine speed. However, LPG shows almost consistent performance throughout the engine speed. Even though the flame speed of LPG is lower than gasoline, it presents reliable BTE and its may be improved by the adjustment of the ignition timing.

Since the energy content of LPG was a little bit higher than gasoline, quantity of gasoline injected was slightly higher than LPG. This is due to the energy compensation in order to produce the same engine output. This is clearly illustrated in Fig. 3 whereby the quantity of fuel injected was directly influenced by the injection duration of each fuel. Injection duration of LPG fuel at all TP was recorded lower than gasoline and the pattern of injection duration were found similar for both fuels. In addition, fuel quantity injected was found increase as the engine TP increase. The brake specific fuel consumption (BSFC) also shown in Fig. 3 where the BSFC also exhibits comparable pattern with BTE where the trade-off between these two fuels was at 3000 engine speed. This exhibits that the engine consumed higher gasoline at below 3000 engine speed but produced lower BTE and vice versa for LPG at all TP.

The brake power produced for both fuels were shown in Fig. 4 and the brake power was increased as the engine speed increase. The brake power produced for both fuels was almost identical at all TP. This is due to the LPG was injected in the liquid form rather than gaseous form. The liquid injection will leads to the benefits of its energy content by improved the volumetric efficiency due to the rapid vaporization that resulting in cooler and denser of the air-fuel mixture flowing into the combustion chamber. In other view, liquid injection of LPG would created the Joule-Thompson effects during the air-fuel mixing process that eventually produced less unburned fuel. 


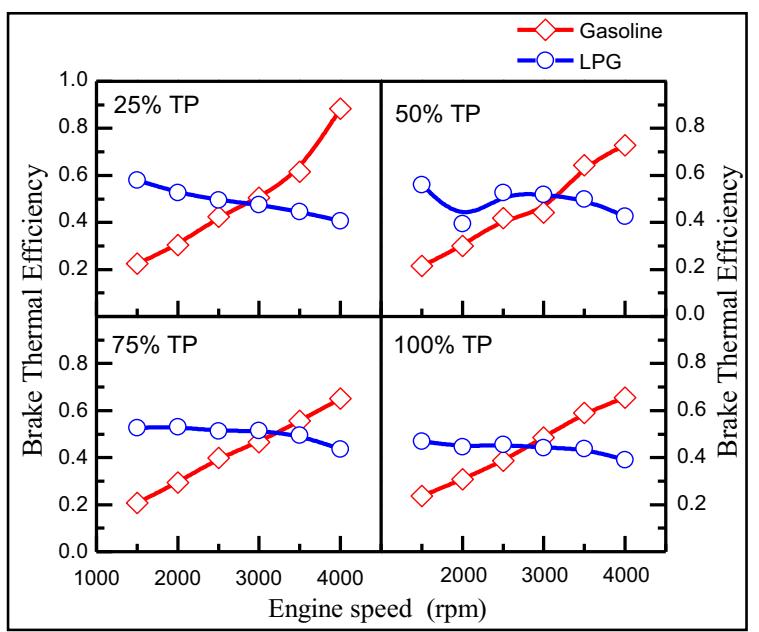

Fig. 2. Brake thermal efficiency of gasoline and LPG at various throttle position.

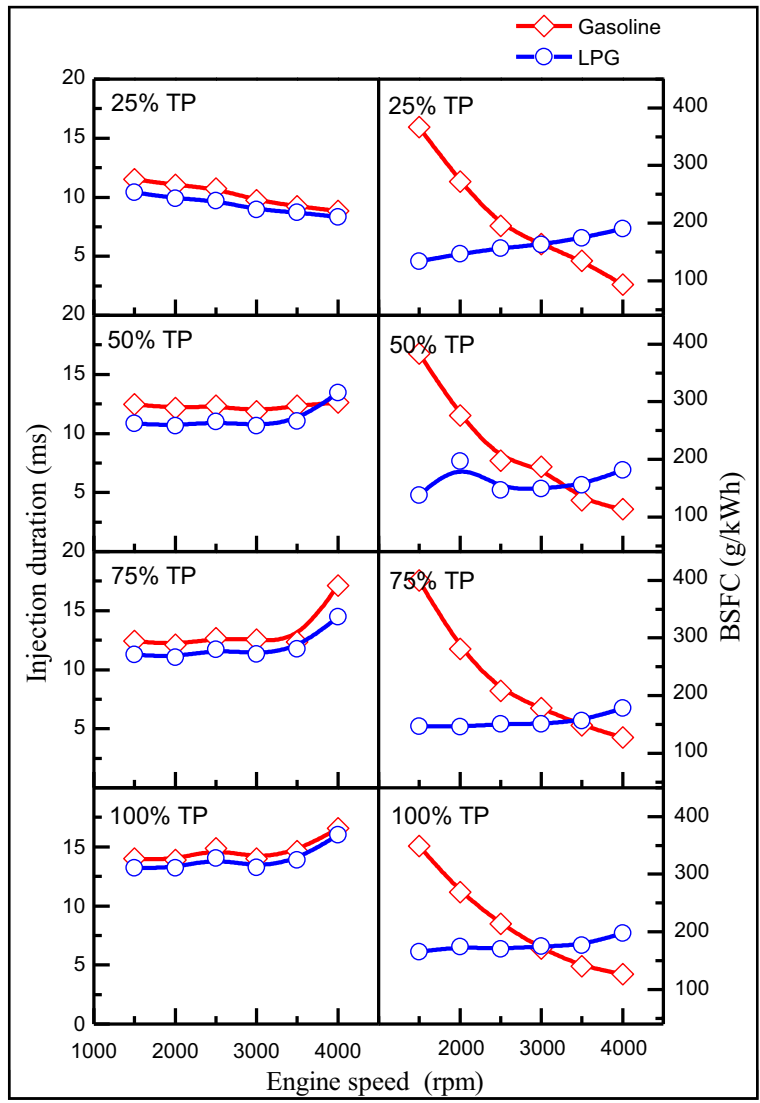

Fig. 3. Injection duration and BSFC of gasoline and LPG at various throttle position. 
For the emissions, carbon monoxide (CO) and hydrocarbon (HC) were analyzed and the data of both gases as per shown in Fig. 5. CO emission at 25\%, 50\% and 75\% showed very lower value and this indicated that the combustion of both tested fuel occurred at lean combustion. However, at $100 \%$ TP, CO was recorded higher throughout the entire engine speed and only at the 4000 engine speed of $50 \%$ and $75 \%$. This is obviously described that incomplete combustion occurred due to less oxygen during combustion.

In general, HC emission of LPG was higher than gasoline at all TP and this HC emission is in agreement with the CO emission. This depicted that lots of LPG was unburned as compared to gasoline especially at $100 \% \mathrm{TP}$. This may be due to the inaccurate spark timing and improper air-fuel mixing. Since the flame speed of LPG was lower than gasoline and energy content of LPG was higher than gasoline, the adjustment and proper setting of spark timing is required in order to fully utilize the LPG properties.

Other than that, the characteristics of air-fuel mixture of the tested engine were analyzed based on the data collected. In general, the air-fuel mixture mapping may be divided into four different conditions based on TP as shown in Table 5. The air-fuel mixture was mapped to the rich condition at $4000 \mathrm{rpm}$ of $50 \%$ and $75 \% \mathrm{TP}$ and also at all engine speed of $100 \% \mathrm{TP}$. This is due to the engine preservation whereby the rich mixture will decrease the combustion temperature and cools the engine that reduced the tendency of engine faulty.

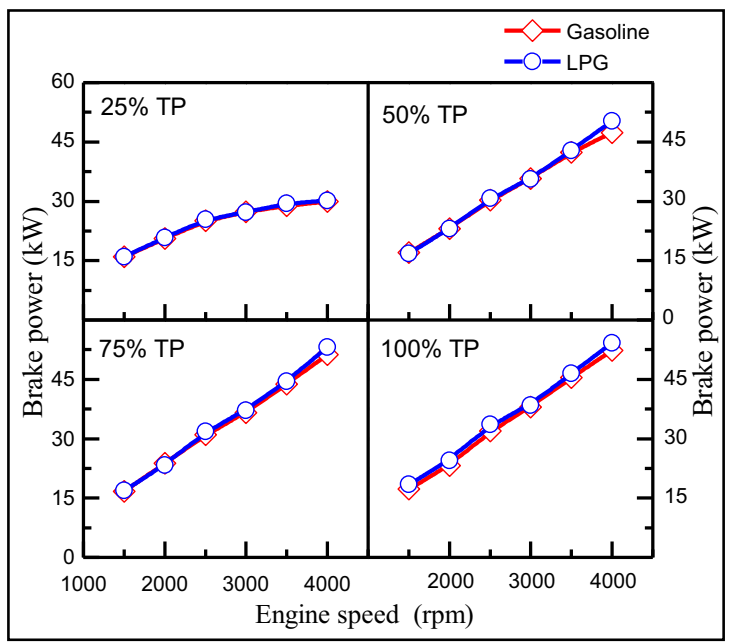

Fig. 4. Brake power of gasoline and LPG at various throttle position.

\section{Conclusions}

Based on the obtained results and some analysis conducted, LPG offers excellent promise as an alternative fuel for the spark ignition engine due to its higher energy content as compared to the gasoline fuel. However, the injection phase and spark timing shall be adjusted to the optimum setting. 


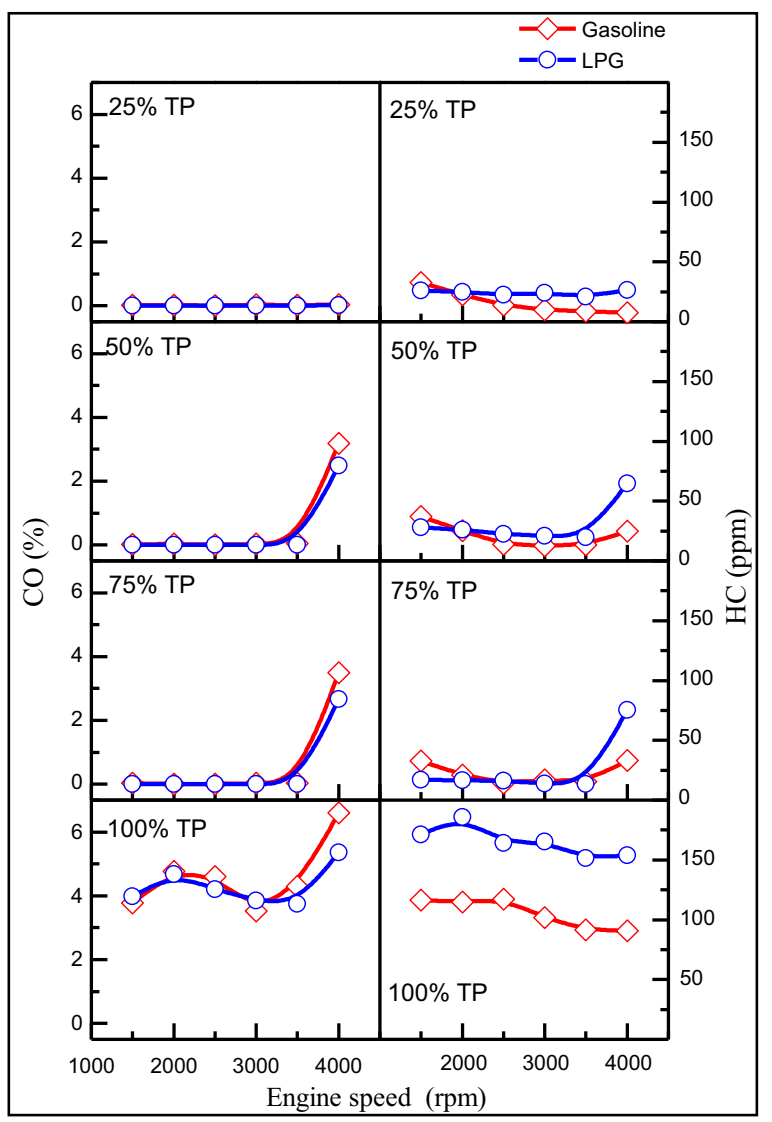

Fig. 5. $\mathrm{CO}$ and $\mathrm{HC}$ emissions of gasoline and LPG at various throttle position.

Table 5. Air-fuel mixture mapping of tested engine at four different TP.

\begin{tabular}{|c|c|c|c|c|c|c|}
\cline { 2 - 7 } \multicolumn{1}{c|}{} & \multicolumn{6}{c|}{ Engine speed (rpm) } \\
\hline $\begin{array}{c}\text { TP } \\
(\mathbf{\%})\end{array}$ & $\mathbf{1 5 0 0}$ & $\mathbf{2 0 0 0}$ & $\mathbf{2 5 0 0}$ & $\mathbf{3 0 0 0}$ & $\mathbf{3 5 0 0}$ & $\mathbf{4 0 0 0}$ \\
\hline 25 & Lean & Lean & Lean & Lean & Lean & Lean \\
\hline 50 & Lean & Lean & Lean & Lean & Lean & Rich \\
\hline 75 & Lean & Lean & Lean & Lean & Lean & Rich \\
\hline 100 & Rich & Rich & Rich & Rich & Rich & Rich \\
\hline
\end{tabular}

The authors would like to thank the Universiti Tun Hussein Onn Malaysia for supporting this research under the Short Term Grant VOT. U383.

\section{References}

1. Autogas Incentive Policies, A country-by-country analysis of why and how goverments promoto autogas and what works. World LP Gas Association. (2012)

2. Pipitone. E, Beccari. S, SAE Technical Paper. (2010)

3. Arcoumanis, C. Bae, C. Crookes, R. Kinoshita. E, Fuel 87, (2008)

4. Kwak, H. Myung, Park, Fuel 86 (2007)

5. Myung, Choi, K. Kim, J. Lim, Y. Lee, Park, Energy 44, 1(2012) 
6. Myung, Kim, J. Choi, K. Hwang, Park, Fuel 94, (2012)

7. Raslavičius, L. Keršys, A. Mockus, S. Keršienè, N. Starevičius, Renewable and Sustainable Energy Reviews 32, (2014)

8. Biscoff, R. Akple, M. Turkson, R. Klomegah, Scenario of the emerging shift from gasoline to LPG fuelled cars in Ghana: A case study in Ho Municipality, Volta Region. Energy Policy 44, (2012)

9. Saraf, Thipse, Saxena, SAE Tech. Pap. (2008)

10. Saraf, Thipse, Saxena, SAE Tech. Pap. (2009)

11. Park, Park, Y. Oh, S. Lee, Y. Kim, T. Y. Kim, Kang, SAE Tech. Pap. (2013). 